\title{
UNCOMMON COMPLICATION OF SLIPPING OF THE UPPER FEMORAL EPIPHYSIS
}

\author{
F. T. WheFldon, London, England
}

From the Department of Orthopaedics, St George's Hospital, London

Although for some time it has been recognised that imperfect results after the reduction of a slipped upper femoral epiphysis may arise from the formation of new bone on the under surface of the neck of the femur, it is thought worth while to record a clear example of the condition where such new bone was removed at operation. It is believed to be the only published record of direct operative attack upon this complication of adolescent coxa vara.

A schoolboy of average build, aged fifteen years, began to complain of weakness and stiffness in the left hip joint, and radiographic examination one month later revealed early slipping of the femoral head. Three days later the boy stumbled when walking, and displacement of the epiphysis was greatly increased (Fig. 1). After one week of balanced traction of $26 \mathrm{lb}$. on the affected limb the downward but not the backward displacement was reduced; under general anaesthesia reduction was completed by gentle manipulation with traction and medial rotation. A trifin nail was then inserted to fix the head slightly

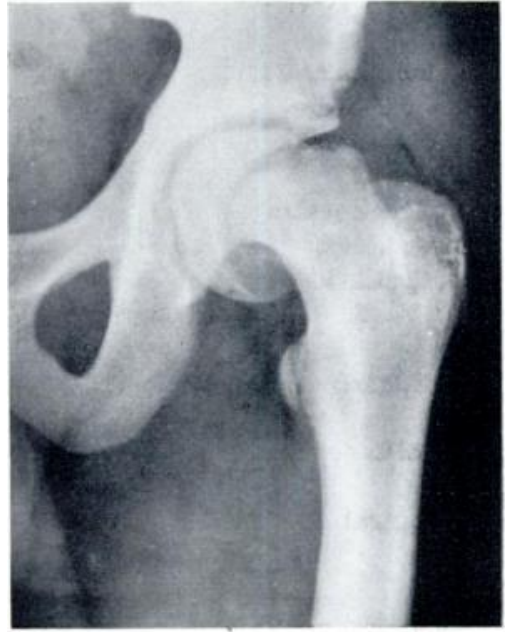

FIG. 1

Before operation.

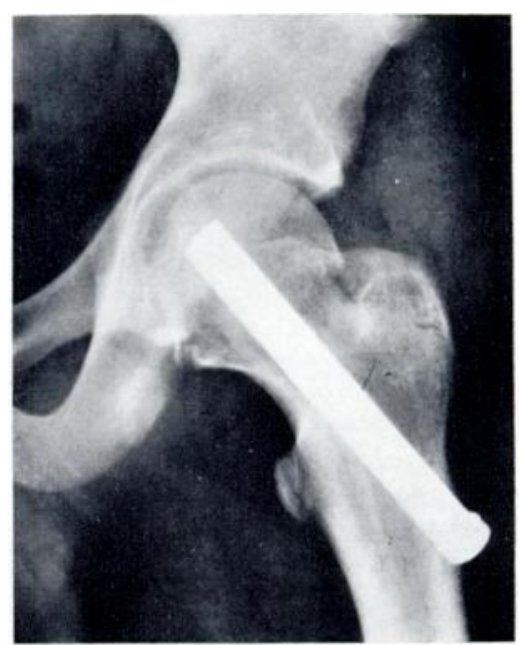

FIG. 2

After nailing.

above and behind the normal position (Fig. 2). The patient was kept in bed for six weeks and thereafter he walked with crutches, without weight bearing on the affected side, for six months. Full weight bearing was then permitted. Nine months after the operation, the epiphysial line having closed, the nail was removed. After that, there was persistent abduction deformity, accompanied after two years by sharp attacks of lumbago which so added to the discomfort resulting from altered gait and posture that further intervention became imperative. Examination-When the boy was standing there was obvious abduction of the left hip joint with tilting of the pelvis and compensatory scoliosis. This abduction was slightly more than $\therefore$ degrees in extension and it disappeared with flexion. There were also a 10 degrees fixed 
flexion deformity and complete loss of medial rotation. A bony prominence was visible in radiographs at the lower end of the upper femoral epiphysial line, apparently impinging upon the acetabulum, and this was thought to be the cause of the deformity and limitation of movement (Fig. 3).

Operation-The hip joint was exposed by an anterior approach with division of the straight head of rectus femoris. The capsule was incised longitudinally to expose the bony boss which had been brought into the bottom of the wound by abduction and lateral rotation of the femur. It was situated at the lowest part of the neck, immediately distal to the margin of the articular cartilage; smoothly covered with periosteum, it had the appearance of a

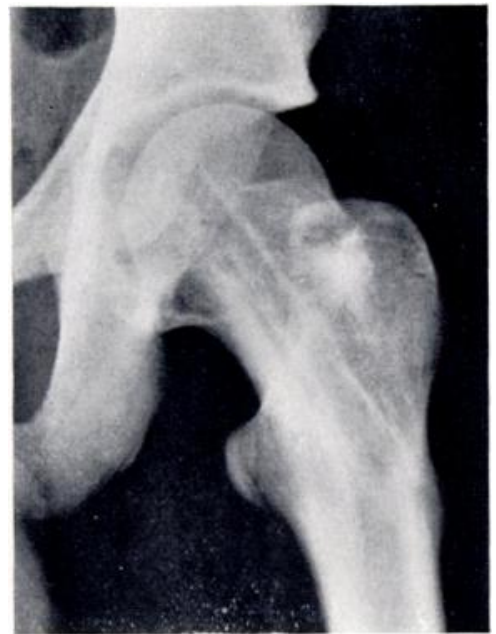

FIG. 3

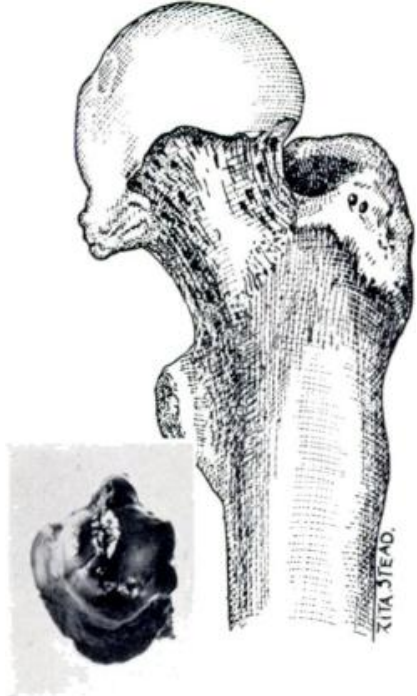

FIG. 4

Figure 3 - Two and a half years after nailing. Note the infero-medial bony projection. Figure 4-Drawing of the bony projection with (inset) a photograph of the bone excised.

simple exostosis. It was removed in one piece (Fig. 4). One month later, adduction movement had increased to 20 degrees and medial rotation to 30 degrees; all other movements were full. Five months later there was only slight limitation of medial rotation. Recently, three years after the operation, the boy has been accepted for military service in the highest medical category.

\section{DISCUSSION}

It is suggested that the new bone formation on the inferior aspect of the femoral neck in this case was due to organisation of callus formed in the angle between the head and neck of the femur in the stage of chronic slipping, the mass being left behind on the prominence of the neck when the head was reduced upwards. Howorth (1949) noted that this callus is formed rapidly; and both Key (1948) and Ferguson and Howorth (1931) advised its removal in open reduction of the displaced epiphysis. Several other workers have described the formation of callus (Key 1926, Wardle 1933, McMurray 1938, Green 1945, Kleinberg 1946) but have not found it to cause symptoms: but MacAusland (1935) mentioned one case in which " a small projection of bone restricts motion, making it impossible for the patient to cross his legs."

Whitman (1909) and Heyman (1949) both described removal of bone from the upper anterior part of the neck by which to increase the range of movement after slipping had ceased, but their cases all had great displacement and the bone removed was part of the normal neck abnormally displaced. The bony boss in the case now reported was perhaps

vol. $35 \mathrm{~B}$, No. 2 , MAY 1953 
increased by the over-correction upwards of the displacement, but that alone does not seem to have been sufficient to account for the exostosis that developed or for the striking deformity that it produced.

I wish to thank .Mr B. H. Burns for permission to describe this case, which was under his care, and for his most generous advice and encouragement.

\section{REFERENCES}

Fergeson, A. B., and Howorth, M. 13. (1931): Slipping of the Upper Femoral Epiphysis: a Study of Seventy Cases. Journal of the American Medical Association, 97, 1867.

Greis, W. T. (1945) : Slipping of the Upper Femoral Epiphysis, Diagnostic and Therapeutic Considerations. Archives of Surgery, 50, 19.

Hermas, C. H. (1949): Treatment of Slipping of the Upper Femoral Epiphysis. Surgery, Gynecology and Obstetrics, 89, 559 .

HoworTH, M. B. (1949): Slipping of the Upper Femoral Epiphysis. Journal of Bone and Joint Surgery, 31-A, 734.

KEY, J. A. (1926) Epiphysial Coxa Vara. Journal of Bone and Joint Surgery, 8, 53.

KEY, J. A. (1948): In discussion on paper, Badgley, C. E., Isaacson, A. S., Wolgamot, J. C., and .Iiller, J. W. Operative Therapy for Slipped Upper Femoral Epiphysis. Journal of Bone and Joint Surgery, 30-A, 29. Kleinberg, S. (1946): Incipient Epiphysiolisthesis of the Hip, its Diagnosis and Treatment. American Journal of Surgery, N.F. 72, 190.

MacAusland, A. R. (1935): Separation of the Capital Epiphysis. Journal of Bone and Joint Surgery, 17, 365. McMurray, T. P. (1938): Slipping of the Upper Femoral Epiphysis and its Treatment. Medical Press and Circular, 197, 346.

WARDLE, E. N. (1933): Etiology and Treatment of Slipped Epiphysis of the Head of the Femur. British Journal of Surgery, 21, 313.

Whitman, R. (1909): Further Observations on Injuries of the Neck of the Femur in Early Life. Medical Record, 75, 1. 